DOI: $10.17805 /$ zpu.2018.1.7

\title{
Тело человека как социокультурный феномен
}

\author{
В. А. РЕМИЗОВ
}

МОСКОВСКИЙ ГОСУДАРСТВЕННЫЙ ИНСТИТУТ КУЛЬТУРЫ,

И. И. ИРХЕН

АКАДЕМИЯ РУССКОГО БАЛЕТА ИМЕНИ А. Я. ВАГАНОВОЙ

В статье предпринята попытка осмыслить тело человека как социокультурный феномен. Для анализа предмета исследования использованы методы включенного наблюдения, контент-анализа, моделирования культурных функций, социокультурной аналогии. Дана трактовка тела человека в виде культурного текста с учетом положений методологии культурной диффузии в части анализа взаимопроникновения культурных инноваций, а также принципов функционализма, рассматривающих культурные процессы как взаимосвязанные между собой элементы антропологической системы. 
На конкретных примерах проанализирована взаимосвязь телесных качеств, техник тела с системой культуры традиционных и современных обществ. Отмечена власть общественных законов, культурных норм над человеческим телом. Показано, что внешний облик людей, их язык, категории восприятия выступают результатом встраивания в тело объективных структур социального пространства. Так как граница физического тела делает его символом, социальной метафорой группы, акцентируется синхронность социокультурного и индивидуально-телесного начала. Уточняются проявления телесной неконгруэнтности, ставшей нормой в современных реалиях. В дискурсе о телесности человека затрагивается тема его энергийности. Телесная организация рассматривается носителем «культурного поля» как особая форма жизни. Отмечена трансформация человеком собственной биологической структуры (тела) в «особой» энергетической среде взаимодействия и функционирования человеческих эмоций, переживаний и чувств. Выдвинут тезис о необходимости эмоциональной энергии всех людей независимо от их принадлежности к тому или иному энерготипу для самого существования культуры. Уровень развитости конкретного культурного ареала во многом определяется мерой духовного развития конкретной человеческой общности, фазой данного этногенеза, силой духа эпохи, в связи с чем обосновывается идея о теле человека как результате социокультурного действия. Тело человека также выступает не пассивной отражательной данностью, а активным фактором социокультурного содержания. Оно фиксируется в языке, образах, афоризмах, метафорах, стилистике действий, культурных практиках - во всей взаимосвязи структурных элементов.

«Человеческое тело - культура» образуют сложную систему, которая проявляется на материальном, духовном, деятельностном уровнях. В условиях технологической революции телесность подвергается активным трансформациям. Рефлексия тела человека в диалектической связи природного и социального начала, их синергии обнаруживает новые возможности синтеза разных паттернов, а шире - социокультурного конструирования телесной человеческой системы.

Ключевые слова: тело человека; техники тела; язык тела; социокультурный анализ; телесность; телесные проявления; социокультурные нормы

\section{ВВЕАЕНИЕ}

$\bigwedge \begin{aligned} & \text { искурсивный социокультурный анализ тела и заботы о его природных и соци- } \\ & \text { альных функциях базируется на исходном культур-антропологическом понима- }\end{aligned}$ нии человека как духовного существа со своим специфическим телом (Быховская, 1993; Орлова, 2004; Розин, 2006). Последнее рассматривается в дихотомиях «биологическое - социальное», «индивидуальное - общественное», выступая неким посредником. Проецирование телесности человека на дихотомию «природное культурное» позволяет обнаружить влияние на людей моды, типажей, имиджей, моделей (массовидных «масок»), наряду со стремлением человека к индивидуальности лица и тела (Костина, 2005, 2013). Аействительно, современные реалии все активнее включают тело в свое поле: оно необходимо для генерации в социокультурной практике широкого спектра эмоций, реализации актов мышления, резервов памяти, спектрирования и интерпретации языков культуры. СМИ деятельно используют тело для навязывания ему культурных эталонов, форм и способов функционирования образцов силы и красоты. Тело становится не только объектом потребительских манипуляций, но и оружием для террористов-смертников.

Наконец, появление виртуального тела, изолированного от реальных контактов, кинесических акций, сенсорных восприятий, позволяет испытывать необычные ощущения посредством интеракции образов, что дематериализует реального телесного человека, маркируя социальное инобытие. Исходя из этого можно утверждать, что сама организация человека, его тело являют собой некий культурный текст, информацию и актора в мире других и Аругого. 
Цель статьи - детализировать понятие тела человека как социокультурного феномена; углубить саму проблематику, которая ранее в большей мере касалась только поведенческих сторон телесности личности.

Статья опирается на междисциплинарный подход. Аля анализа предмета исследования используются положения методологии культурной диффузии в части анализа взаимопроникновения культурных инноваций (Ф. Гребнер), а также принципы функционализма, рассматривающие культурные процессы как элементы антропологической системы, взаимосвязанные друг с другом (Р. Мертон, Т. Парсонс). Методы исследования: анализ и синтез, включенное наблюдение, контент-анализ, моделирование культурных функций, социокультурная аналогия.

\section{СОЦИОКУАБТУРНЫЕ НОРМЫ ТЕАЕСНЫХ ПРОЯВАЕНИЙ}

Научная трактовка тела человека как культурного текста открывает «новые горизонты социального познания» (Романовский, 2006) посредством возможности прочитывать телесность как специфическую книгу. Существуют даже специальные «науки» по данному направлению: хиромантия, жестика, физиогномика, кинесика, визажистика и т. п. Всматриваясь в особенности внешности, в характер и манеру движения, в типы телесных коммуникаций, в каждой культуре можно обнаружить свои нормы телесных проявлений, которые активно видоизменяются во времени-пространстве (Бахтин, 1986). Аоказательством этому служат дошедшие до нас изображения человека древних культур Египта, Греции, Рима, Китая и Южной Америки.

Безусловно, каждая культурно-историческая эпоха демонстрирует свои идеалы и устремления. «Пышность телесных форм женщин на полотнах Рубенса, их застывшие расслабленные позы, мягкая пластика нежных рук сильно контрастирует с изображением европейской женщины конца XX столетия: подтянутое, сухое тело, отточенность поз, ментальность образа» (Никитин, 1998: 138-139). Однако в сознании подавляющего большинства людей и в России, и в Европе представления о силе и энергии связываются с крупными объемами, с массой тела. Так, например, во Франции люди предпочитают видеть в качестве премьер-министра человека полного, упитанного, соответствующего их взглядам на благополучие, достаток $(\mathrm{Pa}$ пай, 2010). Вместе с тем повсюду ценятся подтянутость и спортивная активность: Обама связан с баскетболом, Трамп увлечен бейсболом, Путин занимается борьбой, Шойгу играет в хоккей и т. А.

По утверждениям антропологов, жизненные практики людей конкретной эпохи, опыт их социального бытия формируют не только ментальные характеристики, но и телесные качества. Аействительно, мы можем наблюдать энергичную эмоциональность южан и их неторопливость в труде; эмоциональную сдержанность северян при их деловой расторопности; упорность и детализированность при выполнении задач восточными людьми. Несмотря на внешние проявления, жизненные практики оказывают влияние на способы жестикуляции и характер поз, на формы сексуальности. Так, по резким, рубленым жестам можно распознать русского человека; по манере сидеть «на корточках» можно выделить людей из Средней Азии или с Кавказа. Знаменитая книга «Камасутра» описывает широкую панораму культуры народов Индостана и рядом расположенных этносов. Все это, в свою очередь, позволяет трактовать тело человека как константу общественного бытия, ибо «сугубо природного тела» в отрыве от его «второй природы», культуры, не существует. 
С первых дней жизни природно-биологический уровень тела дополняется «культурными инстинктами», которые определяют поведение человека, его жизненную канву, тем самым подвергая регуляции естественные потребности и функции. Значения жестов, на первых взгляд природою заданных, в реалиях обусловливают социальные и культурные детерминанты. Это позволяет говорить о конвенциональности человеческого тела, выступающего итогом взаимодействия биологического и социокультурного в его функционировании. Оставаясь частью природы, подчиняясь ее физическим и биологическим законам, современный человек в то же время уже не является целиком ее частью, ибо живет в мире культуры и постигает ее.

Рассматривая тело в виде естественного инструмента человека, видный французский социолог, антрополог М. Мосс акцентирует существование совокупности техник тела задолго до появления инструментальных техник. В его работах техники тела трактуются как традиционные действенные акты, отличные от магических, религиозных и символических (Мосс, 2011). Они концентрируют широкий спектр маркеров человека: ходьба, взгляды, сон людей, их передвижения, а шире - позиционирование себя другим и перед другими. В каждой культуре наличествуют бинарные оппозиции движений: дозволенные/недозволенные, естественные/«неестественные» и т. А. Известно, например, что считающийся символом вежливости в армии пристальный взгляд расценивается в повседневной культуре гражданского общества неучтивым и некорректным.

Наряду с гендерным разделением труда, имеется соответствующая дифференциация техник тела. Это проявляется на уровне выбора жестикуляции, предпочтительных поз статики и генетики в пространстве и др. Историки культуры подчеркивают этнические различия техник сна и укрывания тела во время дремы, техник прыжка, плавания, подъема тяжестей, поз расслабления, сосредоточения. Так, к примеру, позу знаменитого роденовского мыслителя может не понять представитель африканских народов, а европеец может не принять за размышления лежачую позу человека азиатского континента.

Культурные различия телесных проявлений явственно прослеживаются и на уровне танца. Ааже в европейской культуре отмечаются исторически сложившиеся разные балетные школы (итальянская, британская, русская и др.), в рамках которых неодинакова постановка корпуса, рук и т. А. Еще большие расхождения в пластике тела можно обнаружить в народном танце, который складывался и развивался под влиянием географических, исторических и социальных условий жизни. Благодаря отражению социальных и әстетических идеалов этноса, его истории, трудовой деятельности, жизненного уклада, обычаев, ментальности, танцевальные формы бытовой народной хореографии выступают как плод коллективного творчества. Воплощаемые в практиках современного танца модели телесности описываются в концептах «идеальное тело», «тело-порог», «тело-событие», «тело-объект», «тело-машина», «тело-симптом», «тело-без-органов» и др. (Курюмова, 2011; Гордеева, 2015). Усвоенные в юности техники тела сохраняются на протяжении всего жизненного пути человека, воспринимаясь в дальнейшем «естественными».

Авижения, кажущиеся на первый взгляд инстинктивными, заданными наследственными структурами, формируются в процессе передачи опыта социального бытия от одного поколения к другому через систему символов и смыслов. Речь преж- 
де всего идет о приемах еды, способах умывания, чистки зубов, удовлетворения естественных надобностей. Аинамику бытия культурной формы человека можно наблюдать на примере формирования тела в зависимости от пищи. Размер частей тела, мускульный тонус, обусловленный характером питания, можно сравнить с личным удостоверением жителей конкретного культурного ареала. Неслучайно, например, в США отмечается обилие людей с избыточным весом. Важно здесь и другое: во время приема пищи европейцы сидят за столом, представители же азиатских культур предпочитают размещаться, сидя на уровне пола, есть руками. Если в европейских странах поза нога на ногу свидетельствует о расслабленности, то на Востоке это недопустимо, ибо показ подошвы обуви считается оскорблением.

Аицо человека текстируется в сознании людей, которое «считывает» определенные маркеры и характеристики людей. Например, злое лицо; доброе лицо; мужественное лицо; трусливое лицо; мягкий взгляд; жесткий взгляд; круглое (русское) лицо; лицо американца (белозубая улыбка) и др.

Крепкие зубы свидетельствуют в сознании окружающих о внутреннем здоровье человека; сильные ноги - о его спортивной культуре. Цвет кожи лица (синюшность, желтизна, бледность) сигнализирует об определенном образе жизни: отношении к алкоголю, курению, наркотикам.

Человеческие губы тоже культурно маркируются как определенный текст. Полные губы наделяют одним смыслом - они связываются с добротой, сочные и яркие - другим, их связывают со страстью. Тонкие, худые губы приписываются желчным, язвительным личностям.

Есть в русском фольклоре метафора: губы бантиком (приятные); есть другой образ: губы-стрелы. Оценивая губной абрис, говорят: жесткий рот, хищный рот, похотливый рот. Все это образцы своеобразных культурных кодов по отношению к внешнему человеку (к его телу).

Так, хищный, горбатый нос, сросшиеся черные густые брови вызывают чувство страха и культурной дистанции. Большой лоб, как считается, бывает у умных, способных и творчески одаренных людей.

Мелкие черты лица соотносят с юго-восточной культурой; крупные - с азиатской; узкие глаза и широкие лица ассоциируются с китайской, бурятской и якутской культурами; крупный нос, губы и цвет лица выдают представителей африканской культуры.

Существуют культурно-бытовые представления о человеке, связанные с его общим абрисом: худой - желчный; полный - ленивый; крепко сложенный - работящий; богатырского сложения - спокойный, добрый. Применительно к телу можно услышать выражения: «мешок с отрубями» или «как молодой олень», или «как газель (козочка)», «как березка», или «как танк» и т. А. Все это своеобразные культурные тексты его тела.

Крупный живот у мужчин свидетельствует не только о возрасте и ожирении, но и о малоподвижном образе жизни.

Пышная грудь женщины читается в сознании как тепло, доброта, как «кустодиевская женщина». Женщины с маленькой грудью текстируются как женщины спортивного стиля, как «модели», как «боттичеллевские женщины».

В то же время культурное обыденное сознание мужчин породило такой текстовый код, как «ноги - это лицо женщины». В свою очередь, культурное сознание 
женщины по-своему воспринимает руки мужчин. Однако есть еще одно. В культурах разных народов и континентов специально «записывается» на теле и собирается определенная информация, считываемая только одноплеменниками. Так, в Китае специальными колодками было принято создавать маленькую женскую ножку госпожи. В африканских племенах с этой целью «создавали» длинные шеи, подпиливали зубы, делали засечки в интимных местах, наносили несмываемой краской определенные знаки, вживляли в тело мелкие предметы. Аругими словами, сигнализировали и сигнализируют, превращая тело в текст культуры.

Широко известно, что кожные узоры индивидуальны для человека, однако их особенность связана еще и с различными этносами, с их культурами. Мало того, рост людей - это маркер разных культур, образа жизни, трудовой деятельности. Наконец, не случайно в одной из популярных песен русского шансона поется: «Я милого узнаю по походке». Походка - это особенность «текста» схемной системы человека. Однако походка - это и его культурный код: блатная, деловая, осторожная, торопливая, мягкая, летящая, шаркающая - это все людские культурные образы. Здесь сразу вырисовывается культурный облик определенной масти, стиля, смысла.

Пальцы рук всегда были в центре внимания культуры. Можно предположить, что они выступали своеобразным культурным инструментом счета для наших далеких предков. Таким образом, они - первая таблица счета, прообраз текста цифрового кода. Сегодня пальцы и руки формируют целый разговорный язык для глухих, а для незрячих - подушечки пальцев оказываются индикаторами письменности. В культурно-текстуальном смысле маленькие изнеженные руки мужчины связываются с интеллигентностью, а грубые, шершавые, крепкие - с личностью человека физического труда. Аля пианистов, скрипачей пальцы рук, наряду с глазами и памятью, переносят нотный текст на инструменты, выполняя, таким образом, своеобразную функцию «опальцованного текста» музыкальной культуры.

«Текст» о здоровье содержится также в роговице глаз, в ногтевых окончаниях, в характере кожных высыпаний различных видов. О здоровье человека считывают информацию с волос, с проб-соскобов. По малейшей части тела можно составить геном человека.

В культуре людей различают и такие телесные «тексты», как әстетико-выразительные, которые, правда, еще имеют на подсознательном уровне утилитарно-воспроизводительный смысл. Это касается, например, абриса тел женщин и мужчин: треугольник вершиной вверх - для женского начала, а наоборот - для мужского.

Известна также «фигура Тугенхольда» в виде удлиненной латинской буквы «S». Ее именуют «фигура красоты». Выразительные верх и низ этого абриса привлекают особей обоего пола, но эта линия еще читается и как «естественная» плодовитость, как половая развитость, как «либидо» (3. Фрейд). В данной связке находится и так называемая ухоженность женщины (или мужчины). Она «читается» как культура внешности, однако в ней расшифровывается и большее: упорядоченность образа жизни, разумная деловитость, культурность в отношении к себе и другим. Вспомним оскаровскую киноленту В. Меньшова «Москва слезам не верит». Героиня фильма остро и неприязненно отреагировала при зрительном контакте с героем А. Баталова на его неопрятность (грязные ботинки). В данном плане актуальны и женский маникюр, и прическа, и разумный макияж. 
Все это дает повод ранжировать тексты тела как «скрытые» и «явные». Так, например, торопливая, «прыгающая» или визгливая речь скрытно информирует о неустойчивости, капризности, нервозности субъекта. Аналогичный характер имеют жесты тела: скрепленные руки на груди - желание скрыться; почесывание бровей - неуверенность, сомнение; сжатые ладони - решительность; поднятый подбородок - гордость, «прыгающие глаза» - неискренность и т. А.

В данном контексте можно также вести речь об искусственно созданном и естественном «языке» текста тела. Галстук, бабочка, брошь, шарфик, костюм, накрашенные губы - искусственны. Ну а все, что определяет телесную плоть человека, - естественные текстуальные структуры, порождающие культурные смыслы.

Таким образом, тело человека есть текст, выраженный в различных формах языка и несущий статус культурного значения.

Человеку как биосоциальному существу присуще стремление к созиданию, «окультуриванию» себя. Это касается видоизменений тела, в том числе и природного, в сторону прибавления либо убавления его отдельных элементов: наращивания ногтей и ресниц, отращивания бороды и усов, выполнения макияжа и моделирования овала лица, избавления от морщин, раскрашивания тела с помощью татуажа и т. А. История запечатлела «язык» «мушек» на лице, «язык» веера, «язык» взгляда.

Можно вспомнить распространенную в культурных практиках знаковость формы прически, бороды, усов. Эпатажно воспринимаемые короткие волосы у мужчин XVIII в. стали для наших современников уже вполне привычными. Существовавший в эпоху русского Просвещения стереотип относительно сбривания бороды неизменно сказывался на культурной идентичности мужчины, его превращении в еретика, растлителя души и тела, неправославного. Между тем оппоненты настаивали, что «ношение бороды связано с желанием четко обозначить половую идентичность» (Буслаев, 1861: 233). Сегодня культурный тренд иной: для светских молодых людей начала XXI в. тенденция к отпусканию бороды, исторически присущая священникам, становится данью моде.

Подчиненность «социальному правилу» обнаруживается и в том, как одеваются люди. Одежда человека - словно экстраполяция его тела, некий инструмент для подчинения социорегулятивной деятельности. «Благодаря своему костюму биологический индивид как бы проецируется на арену общественной жизни» (ИевиСтросс, 1983: 236).

Жесткая закрепленность типа одежды и ее цветовой гаммы в традиционных культурах всегда обеспечивала идентификацию представителей социальных сословий. В современных обществах установить принадлежность человека к той или другой социальной страте сугубо по его одежде оказывается несколько проблематично. Распространенная в обществе потребления одежда прет-а-порте (готовая одежда массового предназначения) позволяет определить место ее приобретения (дизайнерский салон, элитный бутик, гипермаркет, рынок) и тем самым классифицировать потребителя одежды.

Исследования моды, норморегуляций межличностного общения, способов самопрезентации человека оказываются существенными для рефлексии трансформационных процессов в обществе. Недаром сегодня уделяется пристальное внимание так называемому дресс-коду. Те или иные марки автомобилей, часов, обуви по-своему формируют и дополняют физический портрет их владельца. 
Анализ техники человеческого тела взаимосвязан с социокультурным пространством. Согласно позиции историка Ф. Броделя, воображаемое путешествие к Вольтеру и даже продолжительная беседа с ним не вызовут у нас огромного удивления. «В плане идей люди XVIII в. - наши современники; их дух, их страсти все еще остаются достаточно близки к нашим, для того чтобы нам не ощутить себя в ином мире. Но если бы хозяин Ферне оставил нас у себя на несколько дней, нас сильнейшим образом поразили бы все детали повседневной жизни, даже его уход за своей особой. Между ним и нами возникла бы чудовищная пропасть» (Бродель, 2006: 38).

Итак, человек становится человеком, лишь повинуясь определенному правилу, фиксированному коду, установленному закону. Все они вынуждают человека держать свое тело в пределах социальных норм, «проговаривать порядок» (Э. Аюркгейм). Безусловно, всякий человек стремится к «нормальному» внешнему виду, в противном случае подвергаясь определенным рискам, соотносимым с культурной нормой.

\section{ТЕАО КАК «ЗАПИСЬ» ОБЩЕСТВЕННЫХ ЗАКОНОВ}

Концептуально значимым представляется такое явление, как «организация» тела в соответствие с «записью закона на теле» (Фуко, 1999; Серто, 2015). Антропологи различают способы и диапазон этих фиксаций. В дописьменных культурах запись осуществлялась на живом теле (раскраска, тату). Современный нож, наносящий шрамы при инициации, имеет подобное предназначение. «Налаживая» связи между правилами и телами, дубинки полицейских и наручники призваны «вписать» силу закона в тело осуждаемого. В связи с этим можно отметить, что распространенный татуаж тела у современной молодежи - это своеобразная запись их вольности, размытого либерализма или внутреннего изоляционизма, неформальности, отделенности от Аругих.

Традиция записи на теле восходит к сообществам с «политико-идеологическим типом культуры». Известная метафора Шекспира гласит: шкура раба - пергамент, на котором пишет хозяин, а пинки - это чернила. Книга - метафора тела. Обществу мало бумаги, кодифицированные законы оно фиксирует на теле. В результате, человеческое тело преобразуется в символ социального, того, чему дано наименование. Примечательно, что факту страдания от насильственной разметки тела сопутствует удовольствие, что тебя выделили, индивидуализировали. Человек даже может испытывать некую гордость через знаковое воплощение (Фуко, 1999). Это касается всех форм маркировки: клеймения, изоляции, ограничения передвижений конкретного индивида и т. д. Вспомним имена Ассанжа, Сноудена. Они - яркая иллюстрация данного явления в наши дни.

Таким образом, закон «правит телами», преобразуя их в текст, в определенные законодательные таблицы, правила и обычаи, в «актеров драмы», организованной общественным укладом. Аля немецких философов (И. Кант, Г. В. Ф. Гегель) закон не существует вне смертной казни, т. е. деструкции тела в виде абсолютной власти буквы и нормы, концентрирующих воедино юриспруденцию, тело и государство.

Все это представляет определенную инкорпорацию (встраивание в тело) объективных структур социального и ментального уровней. Аанное обстоятельство приводит также к выводу о том, что смысл идентичности человека не исчерпывается 
вербальным выражением, предполагая вариативность телесных и поведенческих паттернов. Недаром говорят: «Сделай шаг, и я скажу - кто ты».

\section{ТЕАО КАК СОЦИААЬНАЯ МЕТАФОРА}

При изучении динамики исторических форм коммуникативных реакций человека антропологи метафорично коррелируют социальные группы и целые общества с превалирующими у них реакциями: грубые, неконтролируемые, разнузданные или точные, смиренные, подчиненные сознанию. Так, способность оказать сопротивление массовым волнениям, проявить хладнокровие, подчиниться табу, утвердить особую активность концентрирует некую фундаментальность в социальном опыте человечества как культурный знак. Отсюда возникают и закрепляются такие метафоры, как «пассионарный народ», «социальные подвижники», «общественные труженики», «всенародные глашатаи», «национальный герой», «народный заступник» и т. А.

Характеристики исторических структур сообществ, ставших предтечей человеку, взаимосвязаны с его телесностью. Как отмечалось ранее, не только общество накладывает отпечатки на телах, тела также оставляют свои следы. При этом речь идет о наследовании истории семьи, племени, рода, общества в целом, которую человек «несет» на протяжении всей жизни.

Примечательно, что сам язык описания форм социального (институций, норм, органов принуждения) берет свое начало в базовых телесных метафорах. Структура тела конструирует соответственную символику, метафорические формы. Тело представляет взаимосвязь между частями организма и организмом как целым. Тело - метафора структурированной системы. Тело - аппарат классификации (Douglas, 2003).

По аналогии с телом складывается блок-схема, формирующая понятия ежедневного опыта. Эта схема дает представление о внутреннем и внешнем, о части и целом. Семья при этом изображается как целое, обладающее своей структурой. Женитьба - созидание целого. Появление детей - складывание полной семьи. Развод - распад целого. В культурном фонде народа известна такая трактовка: муж - голова, жена - шея, дети - цветы, дом - крепость, предки - корни, жизнь цыганка, судьба - злодейка, а любовь - заманка. В России получили распространение метафоры: рука судьбы, пуповина истории, перст судьбы, трагическая поза и т. А. Известны и другие социальные метафоры, основанные на телесности человека: пушечное мясо, живой солдатский материал, офисный планктон, синие воротнички, яйцеголовые. Сегодня появляются новые социокультурные метафоры: озабоченные, майданутые, сбитые самолеты, улетные, шахматисты и т. А.

\section{СООТНЕСЕННОСТЬ СОЦИОКУ АЬТУРНОГО И ТЕАЕСНОГО}

Как показывает практика, соотношение индивидуально телесного и социокультурного устанавливается в физическом и социальном пространстве синхронно.

Человеческое тело тоже подвергается изменениям: меняется осанка из-за использования гаджетов, наблюдается ригидность суставов, сдавленность и малоразвитость грудной клетки, неустойчивость походки. Все это вписывается в нормы существующих реалий, ибо телесная неконгруэнтность становится нормой для поАавляющего большинства людей. И хотя с течением времени взгляды на культуру 
телесности трансформируются, но они пока, к сожалению, носят утилитарный характер. В последние годы в Европе и России активно развивается такое спортивное направление, как бодибилдинг. Разрабатываются сложные тренажеры, оборудуются дорогостоящие спортивные залы, обучается специальный персонал инструкторов. Все это нацелено на культивирование тела с разработанными крупными группами мышц. Самоцелью становится не психосоматическое здоровье, выносливость и подвижность тела, не эстетичность и изящество движений, а гипертрофированность мышечных структур, напыщенность и самоуверенность. Между тем медики констатируют нарушения функций вегетососудистой системы, перегрузки сердца и печени из-за больших статических нагрузок на организм.

Кроме того, установлена связь между уровнем агрессивности человека и культом физической силы. Гиперболизация значения мышечной силы опосредует угасание таких качеств, как сенситивность, чувствительность, аккуратность, внимательность к окружающим, легкость в поведении. Нереализованная вовне накопленная физическая энергия может явиться причиной развития психосоматических заболеваний. Однако в евро-американской цивилизации культ силы не только поощряется, но становится символом совершенства. Атлетический, мускульный тип явно преобладает над астеническим и «пикническим» телосложением (по типологии Э. Кречмера). В социальном отборе по-прежнему доминируют генетические детерминанты, стимулирующие развитие функций выживания в природной агрессивной среде.

Нарастающая мускулизация женщин и феминизация мужчин порождает ряд парадоксов. Известно, что у современных женщин наблюдается сужение тазобедренного отдела тела, увеличение ширины плеч. Среди жителей планеты появляется больше леворуких, возрастает численность близоруких, наблюдается увеличение роста тела, стремление к спортивности. Аевочки (женщины) осваивают мужскую походку, мужские повадки, жестику; мужчины овладевают техникой макияжа, перенимают для своей одежды женские детали кроя и отделки.

\section{ЭНЕРГИЙНОСТЬ ТЕАЕСНОСТИ ЧЕАОВЕКА}

Вместе с тем следует отметить, что современная наука активно вводит в дискурс о телесности человека тему его энергийности. Ученые утверждают, что телесная организация является носителем «культурного поля» как особой формы жизни. Она не имеет определенной формы, ее протяженность, длительность существования и проницательность виртуальны; определяется она «низшими» энергиями (эмоции, переживания, состояния, чувства) через прямую социокультурную деятельность человека (и сообщества людей) (Кравченко, 2017).

Здесь необходимо также подчеркнуть, что в культурном поле как в «особой» энергетической среде взаимодействия и функционирования человеческих эмоций, переживаний и чувств, человек, как «культурное животное», трансформирует собственную биологическую структуру (тело). Эти изменения могут носить объективный характер. По данным социологического исследования в Швеции, люди с высшим образованием живут дольше на пять лет по сравнению с теми, кто подобного образования не имеет (Высшее образование ведет к долголетию, 2012: Электронный ресурс). Известно также, что религиозные аскеты и подвижники, обладающие высокими энергиями своих переживаний, обретают нетленность физического тела. 
Сила «культурного (телесного) поля» измеряется энтузиазмом, вдохновением, интересом, волевым усилием, способностью к внутреннему напряжению. Падение данной «силы» фиксируется депрессией, психологической усталостью, безразличием, унынием, хандрой, тревожным ожиданием. Здесь возникает и другое: «культурные практики». Человеку культуры известны точки акупунктуры. Он прибегает к переключению на хобби, на созерцание природы, на прослушивание музыки. Широко практикуется и реализация деятельностных акций, ибо согласно взглядам К. С. Станиславского, Н. М. Амосова изменение физического действия приводит к изменению психического состояния (Станиславский, 1985; Амосов, 2005).

В современном культурном пространстве под чувственным воздействием «культурного поля» (недовольство собой, стремление к телесному идеалу, веление чувства красоты) люди могут намеренно, по своему вкусу изменять собственное тело: прибегать к пластическим операциям, оптимальному похудению, культуризму, вживлению имплантов, пирсинга, тату и др. В условиях массовизации культуры активно используются косметические практики трансформации тела как «способы обыденного или специализированного визуального преобразования телесности, связанные с живописным, живописно-пластическим оформлением внешнего вида без нарушения биологических структур» (Пронькина, 2017: 11).

Свидетельством силы «культурного поля» человеческой телесности как поля особого духовного воздействия явдяются и факты перекодирования поведения домашних животных, постоянно находящихся в коммуникации с человеком. Так, кошки с интересом могут смотреть телевизионные передачи, собаки «внимают» словам хозяина и «общаются» («переговариваются») с ним, вороны научились кататься зимой на хвосте с заснеженных крыш и куполов церквей, обезьяны овладевают компьютерными операциями, не говоря уже о речевой осознанности некоторых попугаев.

Аругая современная линия темы культуры и тела - киборгизация и компьютеризация телесной сути человека. Речь здесь не идет о евгенике и трансплантации органов (это отдельная социальная тема). Мы имеем в виду концепцию, рассматривающую людей как биомашину (Гурджиев, 2017). Вырабатывая якобы необходимую Аля нужд ближнего космоса энергию, люди уподобляются батарейкам (вспомним фильмы братьев Вачовски из серии «Матрица»). Этим утверждаются взгляды на человека телесного как на биологический компьютер. Безусловно, культуру в качестве социокультурного пространства (или среды) и особого рода энергетического поля в принципе не могут создать пассивные и эмоционально-нейтральные люди-батарейки, люди-машины.

Аумается, что эмоциональная энергия всех людей, невзирая на уровень их духовного развития и принадлежность к тому или иному энерготипу, жизненно необходима для самого существования культуры. Какого уровня развития будет тот или иной культурный ареал, насколько иерархически развитым будет культурный фактор, зависит, конечно, от меры духовного развития конкретной человеческой общности, от фазы данного этногенеза, от силы духа эпохи. Тело же - заряжено и заряжается энергией культуры, оно не только изменяет природу «по мерке своего вида» (Ф. Энгельс), но и является ее детищем, изменяясь и системно развиваясь во времени. 


\section{ЗАКАЮЧЕНИЕ}

Итак, тело человека есть яркое воплощение не только природной, но и социокультурной сферы его бытия. Человеческий облик, образ, имидж, лик, абрис, габитус - все это результат его социокультурного действия. Однако тело человека не есть пассивная «отражательная» данность, а активный фактор социокультурного содержания, фиксирующегося в языке, образах, афоризмах, метафорах, стилистике действий и практиках культуры, т. е. взаимосвязь структурных элементов. «Человеческое тело - культура» есть сложная система, проявляющая на материальном, духовном, деятельностном уровнях.

Тело человека как территория столкновения природы и культуры, «отношенческая матрица социальности» (Мосс, 2011) отличается динамичностью своих параметров: физических, интеллектуальных, эстетических, гендерных и др. В условиях технологической революции телесность подвергается активным трансформациям (компьютерный сосуд, кибернетическая машина, аккумуляторная батарейка, биомашина, энергия культурного поля). Аиалектическая связь природного начала и социального, их синергия обнаруживает сегодня новые возможности синтеза разных паттернов, а шире - социокультурного конструирования телесной человеческой системы.

\section{СПИСОК АИТЕРАТУРЫ}

Амосов, Н. М. (2005) Краткая энциклопедия Амосова. М. : АСТ ; Аонецк : Сталкер. 350 с.

Бахтин, М. М. (1986) Эстетика словесного творчества. М. : Искусство. 445 с.

Бродель, Ф. (2006) Материальная цивилизация, экономика и капитализм, XV-XVIII вв. : в 3 т. М. : Весь Мир. Т. 1.551 с.

Буслаев, Ф. И. (1861) Исторические очерки русской народной словесности и искусства : в 2 т. СПб. : А. Е. Кожанчиков. Т. 1.643 с.

Быховская, И. М. (1993) Человеческая телесность в социокультурном измерении: традиции и современность. М. : РИО ГЦОАИФК. 512 с.

Высшее образование ведет к долголетию (2012) [Электронный ресурс] // Правда. URL: https://www.pravda.ru/news/society/15-02-2012/1108140-education-0/ (дата обращения: 01.08.2017).

Гордеева, Т. В. (2015) Кинестезия в исполнительской практике современного танца // Вестник Академии Русского балета им. А. Я. Вагановой. № 1 (36). С. 87-97.

Гурджиев, Г. И. (2017) В поисках бытия. Четвертый путь к сознанию. М. : София. 253 с.

Костина, А. В. (2005) Телесность как ведущая категория философского дискурса о масскультуре (к проблеме самоотношения) // Мир психологии. № 3. С. 113-118.

Костина, А. В. (2013) Массовая культура как феномен постиндустриального общества. М. : URSS. $362 \mathrm{c}$.

Кравченко, В. В. (2017) Симфония человеческой культуры. М. : Аграф. 384 с.

Курюмова, Н. В. (2011) Современный танец в культуре XX века: смена моделей телесности : автореф. дис. ... канд. культурологии. Екатеринбург. 25 с.

Цеви-Стросс, К. (1983) Структурная антропология : пер. с фр. М. : Наука. 536 с.

Мосс, М. (2011) Общества. Обмен. Аичность: труды по социальной антропологии : пер. с фр. М. : Книжный Аом - Университет. 413 с.

Никитин, В. Н. (1998) Психология телесного сознания. М. : Алетейа. 478 с.

Орлова, Э. А. (2004) Культурная (социальная) антропология : учеб. пособие для вузов. М. : Академический проект. 479 с.

Пронькина, А. В. (2017) Косметические практики трансформации тела человека в системе современной массовой культуры : автореф. Аис. ... А-ра филос. наук. Белгород. 47 с. 
Рапай, К. (2010) Культурный код: как мы живем, что покупаем и почему : пер. с англ. М. : Моск. шк. упр. Сколково ; Юнайтед пресс. 166 с.

Розин, В. М. (2006) Как можно помыслить тело человека, или На пороге антропологической революции // Философские науки. № 5. С. 33-53.

Романовский, Н. В. (2006) Тело человека - новые горизонты социального познания? // Социологические исследования. № 4. С. 16-25.

Серто, М. (2015) Изобретение повседневности : пер. с фр. СПб. : Изд-во Европейского ун-та в Санкт-Петербурге. 330 с.

Станиславский, К. С. (1985) Работа актера над собой. М. : Искусство. Ч. 1. 479 с.

Фуко, М. (1999) Надзирать и наказывать. Рождение тюрьмы : пер. с фр. М. : AdMarginem. $478 \mathrm{c}$.

Douglas, M. (2003) Purity and danger: an analysis of concepts of pollution a taboo. London ; N. Y. : Routledge, VIII, 193 p.

Аата поступления: 12.12.2017 2.

\section{A. REMIZOV \\ Moscow State INSTITUTE OF CULTURE, \\ I. I. IRKHEN \\ VAGANOVA BALLET ACADEMY}

HUMAN BODY AS A SOCIAL AND CULTURAL PHENOMENON

This article attempts to consider the human body as a social and cultural phenomenon. The methodology that was used to analyse the subject matter involves the following methods: participant observation, content analysis, modelling of cultural functions, social and cultural analogy. The interpretation of the human body is given in the form of a cultural text taking into account the methodology of cultural diffusion in terms of the analysis of transfusion of cultural innovations. In addition to this, principles of functionalism considering cultural processes as interlinked elements of the anthropological system are explored.

Specific examples prove the correlation between physical qualities, body techniques and the culture of traditional and modern societies. The power of public laws and cultural rules over the human body is pointed out. It is shown that the way people look, their language, and the categories of perception are the result of objective social space structures embedded in the human body. As the border of a physical body makes it a symbol and a social metaphor of a group, the synchronism of the social, cultural and individual-corporal comes to the fore. Corporal incongruence, which is a typical form of modern realities, is defined. Discourse about human corporality touches upon the problem of "special energy". A carrier of "the cultural sphere" considers corporal organisation as a special form of life. It is noted that a man transforms their own biological structure (body) in a "special" energetic sphere of interaction and functioning of human emotions and feelings. This article puts forward the following thesis: emotional energy of all people, regardless of their "energetic type", is necessary for the existence of culture. The level of development of a particular cultural area is defined in many respects by the measure of spiritual development of the human community, the phase of this ethnogenesis, and the fortitude of the era. This proves the idea of the human body as a result of a social and cultural action. The human body acts not as a passive «reflective» entity, but as an active factor of social and cultural content. It is concentrated in the language, images, aphorisms, metaphors, stylistics of actions, and cultural practices - in all interrelation of structural elements.

The system "human body - culture" is complex and it and reveals itself at the material, immaterial, and practical levels. Under conditions of technological revolution, corporality undergoes active transformations. The reflection of the human body in dialectic connection of the natural and social and their synergy discover new opportunities for the synthesis of different patterns and, on a broader scale, - for social and cultural designing of the corporal human system.

Keywords: human body; body techniques; body language; social and cultural analysis; corporality; corporal manifestations; social and cultural norms 
REFERENCES

Amosov, N. M. (2005) Kratkaia entsiklopediia Amosova. Moscow, AST; Donetsk, Stalker. 350 p. (In Russ.) Russ.)

Bakhtin, M. M. (1986) Estetika slovesnogo tvorchestva. Izd. 2nd ed. Moscow, Iskusstvo. 445 p. (In

Brodel', F. (2006) Material'naia tsivilizatsiia, ekonomika i kapitalizm, XV-XVIII vv. Moscow, Ves' Mir. Vol. 1. 551 p. (In Russ.)

Buslaev, F. I. (1861) Istoricheskie ocherki russkoi narodnoi slovesnosti i iskusstva. St. Petersburg, D. E. Kozhanchikov. Vol. 1. 643 p. (In Russ.)

Bykhovskaia, I. M. (1993) Chelovecheskaia telesnost' $v$ sotsiokul'turnom izmerenii: traditsii i sovremennost'. Moscow, RIO GTsOLIFK. 512 pp. (In Russ.)

Vysshee obrazovanie vedet $\mathrm{k}$ dolgoletiiu (2012). Pravda.ru [online] Available at: URL: https://www.pravda.ru/news/society/15-02-2012/1108140-education-0/ (access data: 01.08.2017). (In Russ.)

Gordeeva, T. V. (2015) Kinesteziia v ispolnitel'skoi praktike sovremennogo tantsa. Vestnik Akademii Russkogo baleta im. A. Ia. Vaganovoi, no. 1 (36), pp. 87-97. (In Russ.) Russ.)

Gurdzhiev, G. I. (2017) V poiskakb bytiia. Chetvertyi put' k soznaniiu. Moscow, Sofiia. 253 p. (In

Kostina, A. V. (2013) Massovaia kul' tura kak fenomen postindustrial' nogo obshchestva. Moscow, URSS. 362 p. (In Russ.)

Kostina, A. V. (2005) Telesnost' kak vedushchaia kategoriia filosofskogo diskursa o masskul'ture (k problem samootnosheniia). Mir psikbologii, no. 3, pp. 113-118. (In Russ.)

Kravchenko, V. V. (2017) Simfoniia chelovecheskoi kul'tury. Moscow, Agraf, 384 p. (In Russ.)

Kuriumova, N. V. (2011) Sovremennyi tanets v kul'ture XX veka: smena modelei telesnosti: Thesis of Diss. ... Candidate of Culturoligy. Ekaterinburg. 25 p. (In Russ.)

Levi-Strauss, K. (1983) Simmetrichno razvernutye izobrazheniia v iskusstve Azii i Ameriki. Strukturnaia antropologiia. Moscow, Nauka. 536 p. (In Russ.)

Mauss, M. (2011) Obshchestva. Obmen. Licbnost': trudy po sotsial'noi antropologii. Moscow, Knizhnyi Dom - Universitet. 413 p. (In Russ.)

Nikitin, V. N. (1998) Psikbologiia telesnogo soznaniia. Moscow, Aleteia. 478 p. (In Russ.)

Orlova, E. A. (2004) Kul'turnaia (sotsial'naia) antropologiia. Moscow, Akadem. proekt. 479 p. (In Russ.)

Pron'kina, A. V. (2017) Kosmeticheskie praktiki transformatsii tela cheloveka $v$ sisteme sovremennoi massovoi kul'tury: Thisis of Dis. ... Doctor of Philosophy. Belgorod. 47 p. (In Russ.)

Rapaj, K. (2010) Kul'turnyj kod : kak my zhivem, chto pokupaem i pochemu. Moscow, Moskovskaya shk. upr. Skolkovo, YUnajted press. 166 p. (In Russ.)

Rozin, V. M. (2006) Kak mozhno pomyslit' telo cheloveka, ili na poroge antropologicheskoi revoliutsii. Filosofskie nauki, no.5, pp. 33-53. (In Russ.)

Romanovskii, N. V. (2006) Telo cheloveka - novye gorizonty sotsial'nogo poznaniia? Sotsiologicheskie issledovaniia, no. 4, pp. 16-25. (In Russ.)

Serto, M. (2015) Izobretenie povsednevnosti. St. Petersburg, Izd-vo Evropeiskogo university v Sankt-Peterburge. 330 p. (In Russ.)

Stanislavskii, K. S. (1985) Rabota aktera nad soboi. Moscow, Iskusstvo, Vol. 1. 479 p. (In Russ.) Russ.)

Fuko, M. (1999) Nadzirat' i nakazyvat'. Rozbdenie tiur' my. Moscow, AdMarginem. 478 p. (In

Douglas, M. (2003) Purity and danger: an analysis of concepts of pollution a taboo. London; New York, Routledge. VIII, $193 \mathrm{p}$.

Submission date: 12.12.2017.

Ремизов Вячеслав Александрович - доктор культурологии, профессор кафедры культурологии и международного культурного сотрудничества Московского государственного инсти- 
тута культуры. Адрес: 141406, Россия, Московская область, Химки, Библиотечная ул., д. 7. Тел.: +7 (985)916-15-25. Эл. алрес: shupik49@mail.ru

Ирхен Ирина Игоревна - доктор культурологии, профессор кафедры философии, истории и теории искусства, заведующая аспирантурой Академии Русского балета имени А. Я. Вагановой. Алрес: 191023, Россия, г. Санкт-Петербург, ул. Зодчего Росси, д. 2. Тел.: +7 (981) 817-64-84. Эл. aspec: irkhen67@gmail.com

Remizov Vyacheslav Aleksandrovich, Doctor of Culturology, Professor, Department of Cultural Studies and Intercultural Communication, Moscow State Institute of Culture. Postal address: 7, Bibliotechnaya St., Khimki, Moscow Region, Russian Federation, 141406. Tel.: +7 (985) 916-15-25. E-mail: shupik49@mail.ru

Irkhen Irina Igorevna, Doctor of Culturology, Professor, Department of Philosophy, History and Theory of Arts, Head of Post-Graduate Studies, Vaganova Ballet Academy. Postal address: 2, Zodchego Rossi St., St.-Petersburg, Russian Federation, 191023. Tel.: +7 (981) 817-64-84. E-mail: irkhen67@gmail.com 